In, "Electroactive Polymers and Rapid Prototyping"

Mat. Res. Soc. Symp. Proc. Vol. 698, 275-280 @ 2002 Materials Research Society

\title{
Laser Direct Writing of Hydrous Ruthenium Dioxide Micro-Pseudocapacitors
}

\author{
Craig B. Arnold ${ }^{1}$, Ryan C. Wartena ${ }^{2}$, Bhanu Pratap ${ }^{1}$, Karen E. Swider-Lyons ${ }^{2}$, and \\ Alberto Piqué ${ }^{1}$ \\ ${ }^{1}$ Materials Science and Technology Division, Code 6372 \\ ${ }^{2}$ Chemistry Division, Code 6171 \\ Naval Research Laboratory, Washington, DC 20375, USA.
}

\begin{abstract}
We are using a laser engineering approach to develop and optimize hydrous ruthenium dioxide $\left(\mathrm{RuO}_{\mathrm{x}} \mathrm{H}_{\mathrm{y}}\right.$ or $\left.\mathrm{RuO}_{2} \cdot 0.5 \mathrm{H}_{2} \mathrm{O}\right)$ pseudocapacitors. We employ a novel laser forward transfer process, Matrix Assisted Pulsed Laser Evaporation Direct Write (MAPLE-DW), in combination with UV laser machining, to fabricate mesoscale pseudocapacitors and microbatteries under ambient temperature and atmospheric conditions. Thin films with the desired high surface area morphology are obtained without compromising their electrochemical performance. The highest capacitance structures are achieved by depositing mixtures of sulfuric acid with the $\mathrm{RuO}_{2} \cdot 0.5$ $\mathrm{H}_{2} \mathrm{O}$ electrode material. Our pseudocapacitors exhibit linear discharge behavior and their properties scale proportionately when assembled in parallel and series configurations.
\end{abstract}

\section{INTRODUCTION}

The manufacture of thin film hydrous ruthenium dioxide pseudocapacitors is generally considered difficult due to the complex materials requirements for an effective, high capacitance power source [1]. The most advantageous morphology for a high capacity pseudocapacitor is a permeable, porous structure leading to a large effective surface area [2,3]. However, the $\mathrm{RuO}_{2} \cdot \mathrm{xH}_{2} \mathrm{O}$ system has the additional concern that the capacitance of the material depends on the processing temperature $[4,5,6]$. These aspects of morphological constraints and processing temperature limitations, in addition to the presence of water in the system have made $\mathrm{RuO}_{2} \cdot 0.5$ $\mathrm{H}_{2} \mathrm{O}$ incompatible with standard vacuum techniques for thin film growth. Instead, recent studies of thin film pseudocapacitors have focused on anhydrous and metal oxide systems [7,8].

We take a unique approach under the Laser Engineered Advanced Power Sources (LEAPS) program at the Naval Research Laboratory, to overcome these difficulties by using a laser direct writing technique, MAPLE-DW $[9,10]$. This technique produces thin films of the hydrous material with the desired morphological properties and without the need for high temperature or lithographic processing following deposition. Instead, pseudocapacitors are arranged through the use of UV laser machining of the deposited films.

A distinct advantage of our technique is the ability to operate under ambient conditions to deposit a mixture of $\mathrm{RuO}_{2} \cdot 0.5 \mathrm{H}_{2} \mathrm{O}$ and a liquid electrolyte. This technique of distributing electrolyte within the electrode is commonly used in the production of larger scale electrochemical power sources, but it is not possible with other thin film techniques such as PVD, CVD, or sol-gel methods. Additionally, the use of liquid sulfuric acid electrolyte as opposed to solid-state materials enables higher proton conductivity in the electrolyte and enhances pseudocapacitor properties [11].

In this paper, we demonstrate the ability to deposit functional micro-pseudocapacitors with energy and power densities commensurate with larger power sources. We capitalize on the 
advantage of an ambient process to mix sulfuric acid into the electrode material during laser transfer to improve the energy qualities in comparison to other organic formulations. Finally, by combining our pseudocapacitors in parallel and series, we are able to achieve proportionately larger capacitance and voltage, respectively.

\section{EXPERIMENT}

Thin film hydrous ruthenium dioxide planar pseudocapacitors are deposited using the MAPLE-DW technique that has been previously described in detail $[9,10]$. Figure 1a shows a schematic of the experimental approach. We use a wet "ink" composed of a liquid vehicle (ethylene glycol, glycerol or sulfuric acid solutions) and the passenger material $\left(\mathrm{RuO}_{2} \cdot 0.5 \mathrm{H}_{2} \mathrm{O}\right)$. The hydrated ruthenium dioxide powder is commercially purchased (Alfa) and prepared by oven heating to $150^{\circ} \mathrm{C}$ for 18 hours prior to ink formulation [12]. This yields a material with the desired water content of $\sim 0.5 \mathrm{~mol} \mathrm{H}_{2} \mathrm{O}$ per mol $\mathrm{RuO}_{2}$ [4]. A frequency-tripled $\mathrm{Nd}$ :YAG laser $(\lambda=355 \mathrm{~nm})$ is used to irradiate the back of the ribbon inducing a forward transfer of material to a substrate below the ribbon.

The substrate is a $1 \mathrm{~cm} \times 1 \mathrm{~cm}$ gold-coated quartz wafer that has been laser machined with a $9 \mathrm{~mm}$ "window pane" structure to electrically isolate four contact pads (figure 1b). Deposited material spans across the machined groove in two $1 \mathrm{~mm} \times 2 \mathrm{~mm} \times 10 \mu \mathrm{m}$ pads. A line is then laser machined across both pads providing two symmetric planar pseudocapacitors each with 0.5 $\mathrm{mm} \times 2 \mathrm{~mm} \times 10 \mu \mathrm{m}$ electrodes. The volume of each pseudocapacitor is $2 \times 10^{-5} \mathrm{~mL}$ and the approximate mass is $50 \mu \mathrm{g}$.

The deposited films retain a significant amount of vehicle following laser transfer, which enables the deposited material to achieve a relatively flat, pinhole-free surface. However, the excess vehicle must be removed prior to laser machining in order to obtain sharp structures. In the case of the organic vehicles, we dry the as-deposited films on a hot plate at $100{ }^{\circ} \mathrm{C}$ for 10 minutes prior to laser machining. After the films are machined, the remaining vehicle is removed from the samples by heating in an oven at $5^{\circ} \mathrm{C} / \mathrm{min}$ to $150{ }^{\circ} \mathrm{C}$ and held for 3 hours. In the case of sulfuric acid, the final bake is not used.
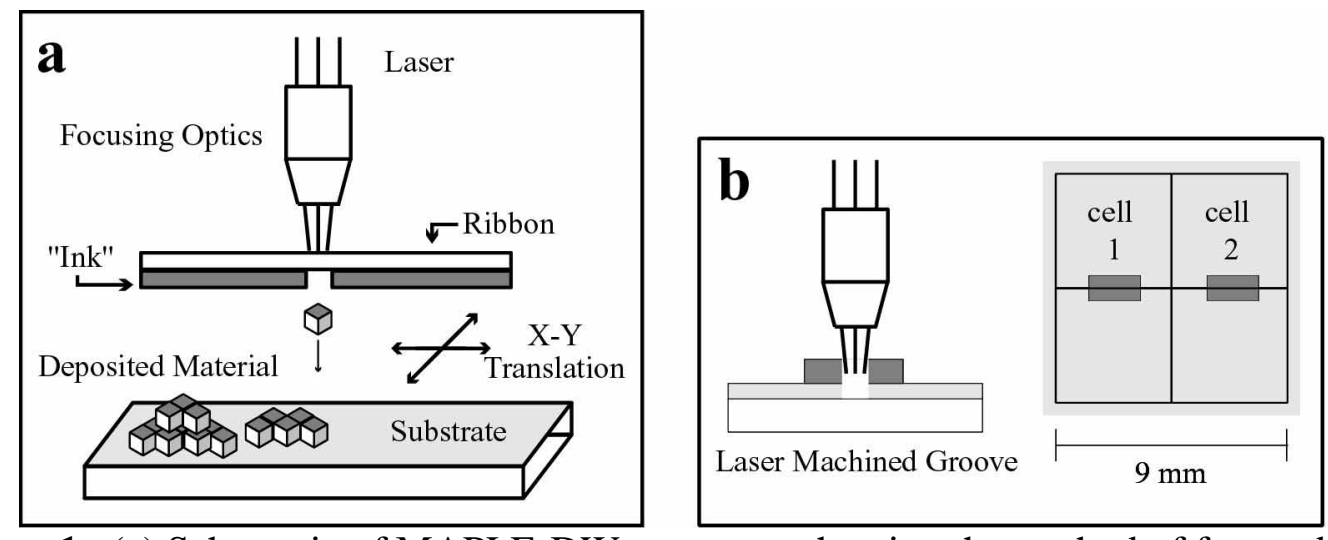

Figure 1. (a) Schematic of MAPLE-DW apparatus showing the method of forward laser transfer of an "ink" layer (b) Sample geometry: the two pseudocapacitors cells are $1 \mathrm{~mm} \times 2 \mathrm{~mm} \times 10 \mu \mathrm{m}$ prior to laser machining. 
Electrochemical evaluation of capacitance and charge-discharge behavior is carried out using a potentiostat (EG\&G PAR Model 263) connected to a probe station. The pseudocapacitors are encapsulated in $\mathrm{Nafion}^{\circledR}$ to provide structural support and submerged in 0.5 $\mathrm{M} \mathrm{H}_{2} \mathrm{SO}_{4}$ solution during testing. Multiple chronopotentiometry (CP) steps are used to charge and discharge the pseudocapacitors between 0 and $1 \mathrm{~V}$ in a two-electrode configuration. For the results presented here, all samples were charged at a constant current of $50 \mu \mathrm{A}$ and discharged at either $10 \mu \mathrm{A}$ or $100 \mu \mathrm{A}$.

\section{RESULTS}

Hydrous ruthenium dioxide films deposited and processed by our technique exhibit desirable morphologic qualities of a pseudocapacitor. Figure 2 shows optical and electron micrographs of the deposited material. The optical image (figure $2 \mathrm{a}$ ) shows that we are able to deposit flat, uniform pads of $\mathrm{RuO}_{2} \cdot 0.5 \mathrm{H}_{2} \mathrm{O}$ and laser machine them with a large degree of precision $(<20 \mu \mathrm{m}$ groove). Our studies indicate that under these processing conditions, there is no collateral damage to the area surrounding the groove.

Under high magnification (figure 2b,c), we see the deposited thin film is highly porous throughout the active material. We find this morphology to be independent of the particular transfer vehicle used. Furthermore, the laser machining process does not damage this microstructure in the region near the groove as shown in figure $2 \mathrm{c}$. This morphology is desirable as it provides a large effective surface area and enables the electrolyte to easily permeate the electrode, which provides high ionic transport to the active material. The high level of electrode porosity is not detrimental to the electronic transport since $\mathrm{RuO}_{2} \cdot 0.5 \mathrm{H}_{2} \mathrm{O}$ is a metallic conductor.

The ultimate test for any of our pseudocapacitors is the electrical response of the power source and its ability to store and deliver charge. Figure 3 a shows the $10 \mu \mathrm{A}$ discharge profiles for samples transferred with three different vehicles (ethylene glycol, glycerol and sulfuric acid solutions). In all cases, the potential vs. time curve is linear as expected for an ideal capacitor. Samples deposited from inks containing $\mathrm{H}_{2} \mathrm{SO}_{4}$ exhibit the longest discharge time, $850 \mathrm{~s}$, as

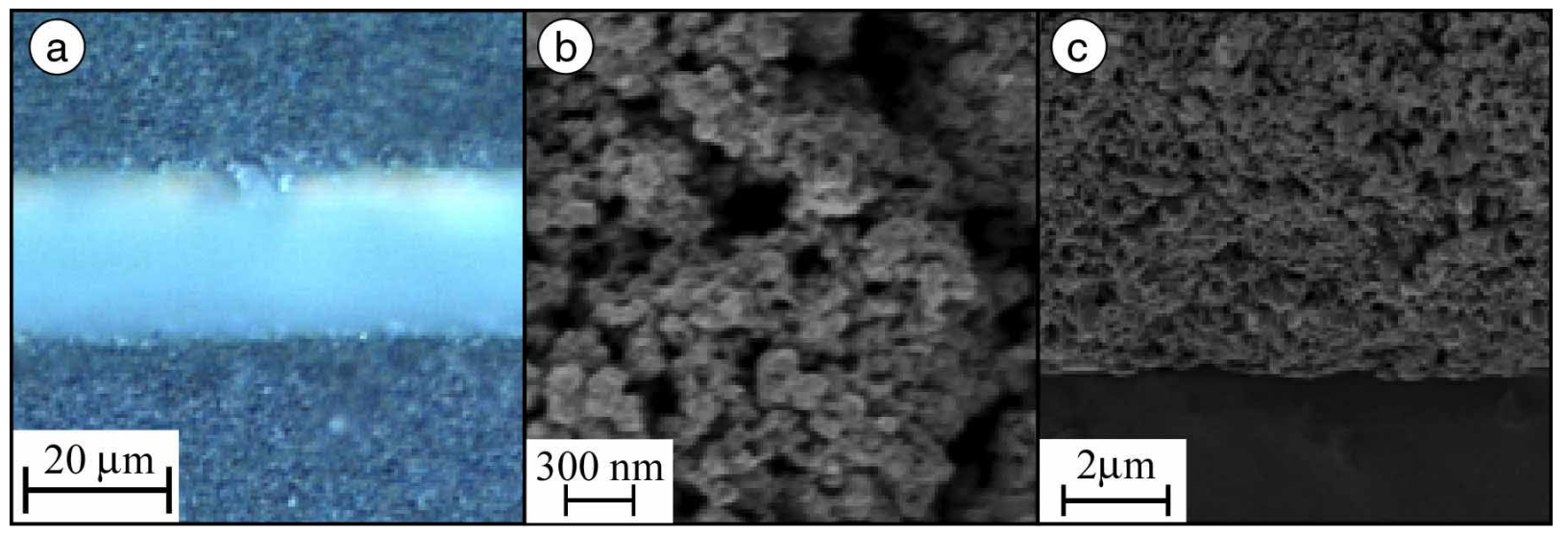

Figure 2. Micrographs of deposited $\mathrm{RuO}_{2} \cdot 0.5 \mathrm{H}_{2} \mathrm{O}$ thin films (a) Optical image at $50 \mathrm{x}$ magnification showing laser machined groove (light colored region). Scale bar is $20 \mu \mathrm{m}$. (b) SEM image of main pad at 20,000x magnification. Scale bar is $300 \mathrm{~nm}$. (c) SEM image near machined groove (bottom of image) magnified 3000x. Scale bar is $2 \mu \mathrm{m}$. 


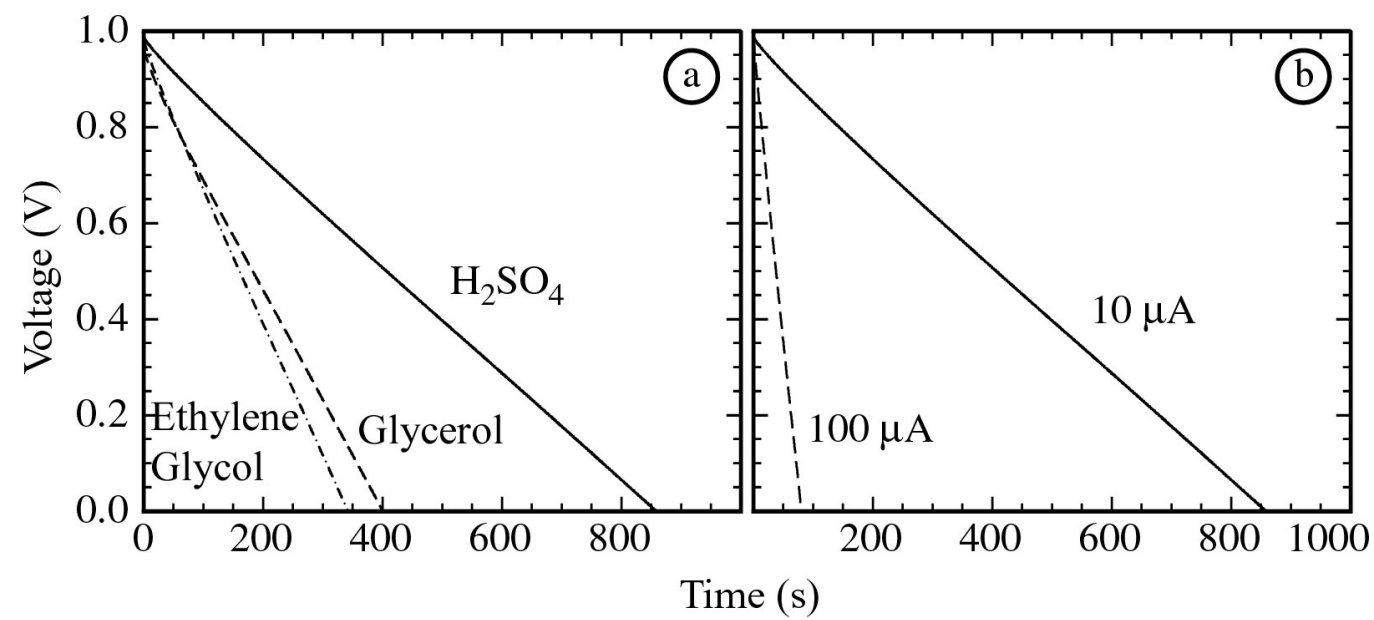

Figure 3. (a) Constant current discharge behavior for $\mathrm{RuO}_{2} \cdot 0.5 \mathrm{H}_{2} \mathrm{O}$ pseudocapacitors deposited from different vehicle solutions at $10 \mu \mathrm{A}$. (b) Discharge curves for sulfuric acid vehicle samples at 10 and $100 \mu \mathrm{A}$. Samples are charged to $1 \mathrm{~V}$ at $50 \mu \mathrm{A}$ prior to discharge.

compared to those deposited from glycerol and ethylene glycol based inks that lasted 400 and 350 s respectively.

If we assume a constant capacitance, which is justified by the linear discharge behavior, then the average specific capacitance of the sample is given by

$$
c=\frac{I \Delta t}{m \Delta V},
$$

where $I$ is the constant discharge current, $\Delta t$ is the total discharge time, $\Delta V$ is the maximum potential difference, and $m$ is the mass of the pseudocapacitor including electrolyte.

Furthermore, we can obtain the specific energy, $\varepsilon$, and average specific power, $p$, from the area under the curve by

$$
\begin{aligned}
\varepsilon & =\frac{I}{m} \int V d t \\
p & =\frac{\varepsilon}{\Delta t} .
\end{aligned}
$$

Table I shows the calculated values of specific capacitance, specific energy and specific power for the data shown in figure 3. Pseudocapacitors transferred using a sulfuric acid vehicle exhibit superior electrochemical characteristics in comparison to those deposited using organic transfer vehicles. Although organic vehicles are advantageous for making stable ink formulations, the deleterious effects of oxidation and decomposition of residual organics in the

\begin{tabular}{|c|c|c|c|c|}
\hline $\begin{array}{c}\text { Transfer } \\
\text { Vehicle }\end{array}$ & $\begin{array}{c}\text { Discharge } \\
\text { Current } \\
(\mu \mathrm{A})\end{array}$ & $\begin{array}{c}\text { Specific } \\
\text { Capacitance } \\
(\mathrm{F} / \mathrm{g})\end{array}$ & $\begin{array}{c}\text { Energy } \\
\text { Density } \\
(\mathrm{mWh} / \mathrm{g})\end{array}$ & $\begin{array}{c}\text { Average } \\
\text { Power } \\
\text { Density } \\
(\mathrm{mW} / \mathrm{g})\end{array}$ \\
\hline $\mathrm{H}_{2} \mathrm{SO}_{4}$ & 10 & 174 & 23.0 & 96.5 \\
\hline Glycerol & 10 & 83.0 & 10.4 & 93.5 \\
\hline Ethylene Glycol & 10 & 69.5 & 9.15 & 96.3 \\
\hline $\mathrm{H}_{2} \mathrm{SO}_{4}$ & 100 & 163 & 21.3 & 953 \\
\hline
\end{tabular}

Table I. Calculated values of specific capacitance, energy density and average power using equations 1-3 and the data shown in figure 3 . 
presence of the acidic electrolyte may cause contamination to the electrically active hydrous ruthenium dioxide. Conversely, the sulfuric acid vehicle produces electrodes with the desired electrolyte already present and eliminates the possibility for contamination from the transfer vehicle.

When the discharge current is increased to $100 \mu \mathrm{A}$ (figure $3 \mathrm{~b}$ ), the specific power increases without significantly affecting the specific energy. The discharge time for a sample deposited with a sulfuric acid vehicle under these conditions is $80 \mathrm{~s}$, which corresponds to a specific power of nearly $1000 \mathrm{~W} / \mathrm{g}$ and a specific energy of $21 \mathrm{~mW} / \mathrm{g}$. These values for specific energy and power compare favorably to literature values for other pseudocapacitor systems [13].

Further evidence of process viability is demonstrated when the pseudocapacitors are connected in parallel and series. Figure 4 shows $10 \mu \mathrm{A}$ discharge profiles for two pseudocapacitors deposited with sulfuric acid and connected in parallel. Again, the system is charged to $1 \mathrm{~V}$ and the discharge curves exhibit linear behavior. However, this parallel configuration has an extended discharge time of $1660 \mathrm{~s}$. Further calculations show the specific capacitance of the system is additive, as expected for capacitors in parallel, while the specific energy reflects the average of the two individual cells.

Pseudocapacitor cells are also combined in series to increase the voltage of the system. In this case (the data is not shown here), we charge the system to $2 \mathrm{~V}$ at $50 \mu \mathrm{A}$. Upon discharge at $10 \mu \mathrm{A}$ to $0 \mathrm{~V}$, we do not find significant changes in specific energy or specific power. The calculation of capacitance from this system exhibits the expected inverse addition rules of series capacitors.

\section{SUMMARY}

We have demonstrated that using a laser engineering approach to develop micropseudocapacitors is a viable method. Micro-pseudocapacitors of hydrous ruthenium dioxide electrodes and sulfuric acid electrolyte are successfully produced using an ambient forward laser

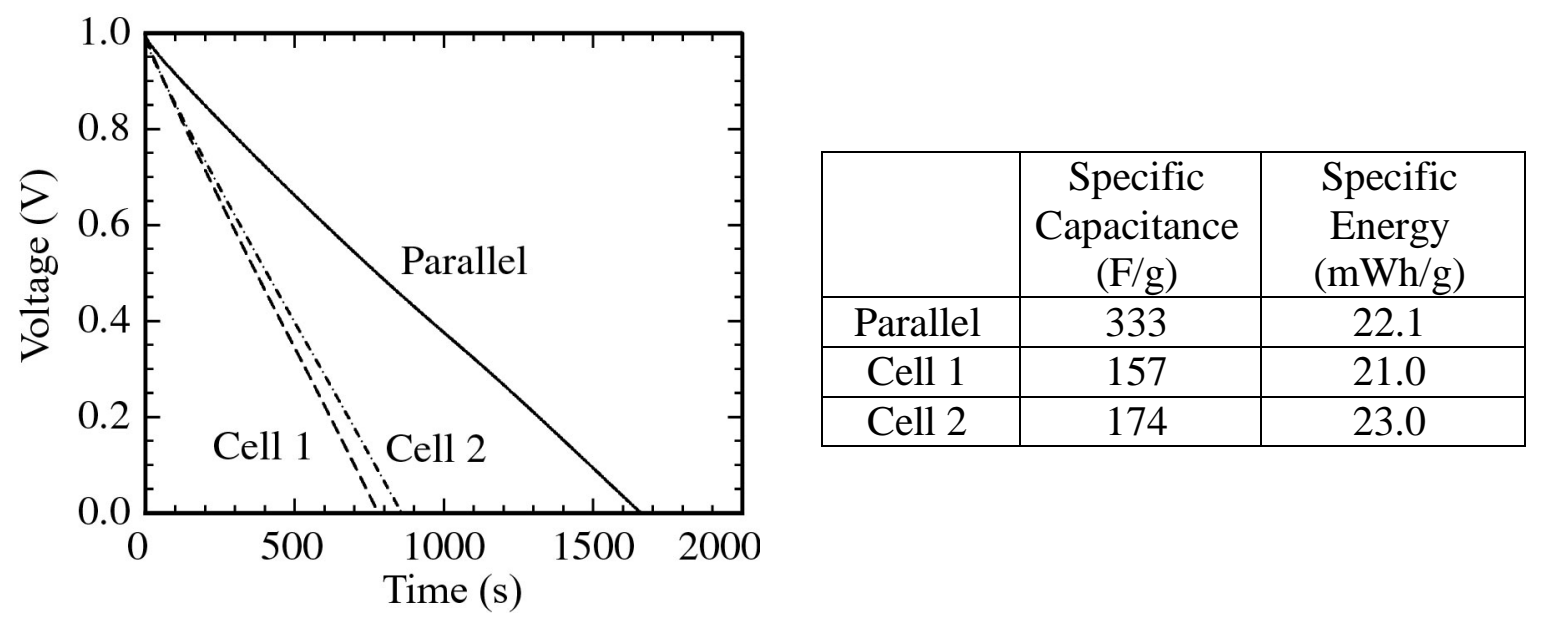

Figure 4. Constant current discharge curves for two pseudocapacitor cells measured separately and in parallel. The cells are charged to $1 \mathrm{~V}$ at $50 \mu \mathrm{A}$ and discharged at $10 \mu \mathrm{A}$. Sulfuric acid is used as the transfer vehicle in these samples. The tabulated values are calculated using equations 1 and 2 . 
transfer technique (MAPLE-DW) in addition to UV laser machining. The evaluation of two different organic transfer vehicles and sulfuric acid transfer vehicle indicates that the choice of sulfuric acid enhances the electrochemical properties of the pseudocapacitors. Configurations of $\mathrm{RuO}_{2} \cdot 0.5 \mathrm{H}_{2} \mathrm{O}$ pseudocapacitors in series and parallel exhibit the expected additive behavior. To our knowledge, these results represent the first demonstration of high specific energy thinfilm hydrous ruthenium dioxide pseudocapacitors incorporating a sulfuric acid electrolyte.

\section{ACKNOWLEDGEMENTS}

This research was supported in part by the Office of Naval Research. CBA acknowledges the support of the National Research Council postdoctoral associate program and RCW acknowledges the support of the American Society for Engineering Education.

\section{REFERENCES}

1. S. Sarangapani, B.V. Tilak, and C.P. Chen, J. Electrochem. Soc., 146, 3791 (1996)

2. S. Trasatti and P.Kurzweil, Plat. Met. Rev. 38, 46 (1994)

3. B.E. Conway, V. Birss, and J. Wojtowicz, J. Power Sources, 66, 1 (1997)

4. J.P. Zheng, P.J. Cygan, and T.R. Jow, J. Electrochem. Soc., 142, 2699 (1995)

5. D.A. McKeown, P.L. Hagans, L.P.L. Carette, A.E. Russell, K.E. Swider, D.R. Rolison, J. Phys. Chem. B., 1034825 (1999)

6. K.E. Swider-Lyons, K.M. Bussmann, D.L. Griscom, C.T. Love, D.R. Rolison, in Solid State Ionic Devices II-Ceramic Sensors, eds. E.D. Wachsman, W. Weppner, E. Traveda, P. Vanysek, N. Yamazoe, M.L. Liu (Electrochem. Soc. 2000-32, 2000) pp 148-156

7. Y.S. Yoon, W.I. Cho, J.H. Lim, and D.J. Choi, J. Power Sources, 101, 126 (2001)

8. K.C. Lin, M.A. Anderson, J. Electrochem. Soc., 146, 124 (1996)

9. R.C.Y. Auyeung, H.D. Wu, R. Modi, A. Piqué, J.M. Fitz-Gerald, H.D. Young, S. Lakeou, R. Chung, and D.B. Chrisey, in Laser Precision Microfabrication, eds. I. Miyamoto, K. Sugioka, T.W. Sigmon (SPIE 4088, 2000) pp. 393-396

10. D.B. Chrisey, A. Piqué, J.M. Fitz-Gerald, R.C.Y. Auyeung, R.A. McGill, H.D. Wu, and M. Duignam, Appl. Surf. Sci, 154-155, 593 (2000)

11. W.G. Pell and B.E. Conway, J. Power Sources, 96, 57 (2001)

12. K.E. Swider-Lyons, D.W. Weir, C.T. Love, R. Modi, T. Sutto, A. Piqué, and D.B. Chrisey, in Power Sources for the New Millennium, eds. M. Jain, M.A. Ryan, S. Surampudi, R.A. Marsh, G. Najarjan (Electrochem. Soc. 2000-22, 2000) pp. 272-276

13. R. Kotz and M. Carlen, Electrochimica Acta, 45, 2483 (2000) 